\title{
Anesthetic management of a patient with polycythemia vera undergoing emergency repair of a type-A aortic dissection and concomitant coronary artery bypass grafting -a case report-
}

\author{
Hyeongwoo Im, Jeong Jin Min, Jaeyoung Yang, Sangmin Maria Lee, and \\ Jong Hwan Lee \\ Department of Anesthesiology and Pain Medicine, Samsung Medical Center, Sungkyunkwan University School of \\ Medicine, Seoul, Korea
}

Polycythemia vera is a chronic progressive myeloproliferative disease characterized by increased circulating red blood cells, and the hyperviscosity of the blood can lead to an increased risk of arterial thrombosis. In a previous survey regarding postoperative outcomes in polycythemia vera patients, an increased risk of both vascular occlusive and hemorrhagic complications have been reported. Aortic surgery involving cardiopulmonary bypass may be associated with the development of a coagulopathy, and as a result, the occurrence of thrombotic complications should be avoided after coronary anastomosis. Thus, optimizing the hemostatic balance is an important concern for anesthesiologists. However, only a few cases of anesthetic management in polycythemia vera patients undergoing concomitant aorta and coronary arterial bypass surgery have ever been reported. Here, we experience a polycythemia vera patient who underwent an emergency repair of a type-A aortic dissection and concomitant coronary artery bypass grafting, and report this case with a review of the relevant literature.

Key Words: Acute normovolemic hemodilution, Aortic dissection, Coronary artery bypass grafting, Hemostatic balance, Polycythemia vera, Thromboelastometry.

Corresponding author: Jeong Jin Min, M.D.

Department of Anesthesiology and Pain Medicine, Samsung Medical Center, Sungkyunkwan University School of Medicine, 81, Irwon-ro, Gangnam-gu, Seoul 06351, Korea

Tel: 82-2-3410-6590, Fax: 82-2-3410-0361

E-mail: prudence2@hanmail.net

Received: January 22, 2015.

Revised: 1st, March 14, 2015; 2nd, April 9, 2015.

Accepted: April 12, 2015.

Korean J Anesthesiol 2015 December 68(6): 608-612 http://dx.doi.org/10.4097/kjae.2015.68.6.608
Polycythemia vera is a chronic progressive myeloproliferative disease characterized by increased circulating red blood cells, and the hyperviscosity of the blood can lead to an increased risk of arterial thrombosis [1]. In a previous survey regarding postoperative outcomes in polycythemia vera patients, an increased risk of both vascular occlusive and hemorrhagic complications have been reported [2,3]. Here we experience a polycythemia vera patient who underwent an emergency repair of a type-A aortic dissection and concomitant coronary artery bypass grafting, and report this case with a review of the relevant literature.

(c) This is an open-access article distributed under the terms of the Creative Commons Attribution Non-Commercial License (http://creativecommons.org/ licenses/by-nc/4.0/), which permits unrestricted non-commercial use, distribution, and reproduction in any medium, provided the original work is properly cited. 


\section{Case Report}

A 73 year old man, $158 \mathrm{~cm}$ and weighing $52.8 \mathrm{~kg}$, was scheduled for an emergency repair of a type-A aortic dissection and concomitant coronary arterial bypass grafting. Hypertension and a transient ischemic infarct (TIA) that occurred 3 years ago were under conservative treatment. He had undergone aortic valve replacement surgery for severe aortic stenosis 26 years earlier, and also had had percutaneous coronary stents inserted in the left circumflex artery and right coronary artery 10 years earlier for coronary stenosis.

In a preoperative review of his chest computed tomography, dissection from the sinotubular junction of the ascending aorta to the aortic arch with a large intimal defect was observed. Preoperative transthoracic echocardiography showed preserved left ventricular function with an ejection fraction of 57\%. Stenotic lesions requiring concomitant coronary arterial bypass grafting were discovered at the initial coronary aorta CT scan. Although a coronary angiogram can be a risky procedure in an aortic dissection patient, his vital signs were stable and it was necessary to evaluate a more accurate range of the stenotic lesions. 50\% left circumflex artery occlusion and total occlusion of the right coronary artery was confirmed with a coronary angiogram. Duplex sonography in the carotid artery showed $<50 \%$ stenosis in both internal carotid arteries. His preoperative blood tests showed abnormally increased levels of hemoglobin $(20.4 \mathrm{~g} / \mathrm{dl})$, hematocrit $(61.8 \%)$, white blood cell count $\left(297,000 / \mathrm{mm}^{3}\right)$, and platelets $\left(406,000 / \mathrm{mm}^{3}\right)$. In his conventional coagulation test, the international normalized ratio of prothrombin time (1.33) and activated partial thromboplastin time (60.6 s) were slightly prolonged, and his fibrinogen level was slightly higher than the upper end of the institutional normal range (384 mg/dl). He had not been diagnosed with polycythemia vera previously, however, the results of his blood tests such as thrombocytosis (> 400,000 platelets $\left./ \mathrm{mm}^{3}\right)$ and leukocytosis $\left(>120,000 / \mathrm{mm}^{3}\right)$ suggested that he had polycythemia vera.

In the operating room, monitoring included a five-lead electrocardiogram with continuous ST segment analysis, pulse oximetry, non-invasive blood pressure, arterial blood pressure with left radial arterial catheter, bispectral index, and a cerebral oximetry. Initial vital signs, checked in the operating room, were stable with a blood pressure of 130/66 $\mathrm{mmHg}$ and a heart rate of $85 \mathrm{bpm}$. Anesthesia was induced and maintained with a continuous infusion of propofol, remifentanil, and cisatracurium. Following endotracheal intubation, transesophageal echocardiography was performed to evaluate cardiac function and to guide the hemodynamic treatment. A triple-lumen catheter with introducer (Advanced Venous Access ${ }^{\circledR}$, Edward Lifescience, Irvine, CA, USA) was placed in the right internal jugular vein by a sono-guided technique, and a pulmonary artery catheter (SwanGanz catheter ${ }^{\circledR}$, Edward Lifescience, Irvine, CA, USA) was also inserted.

Intraoperative baseline arterial blood gas analysis showed a hematocrit level of $61 \%$ and a hemoglobin level of $20.6 \mathrm{~g} / \mathrm{dl}$. To perform acute normovolemic hemodilution (ANH), 1.5 units $(650 \mathrm{ml})$ of whole blood was drawn and replaced with $650 \mathrm{ml}$ of $6 \%$ hydroxyethylstarch solution (HES, Volulyte ${ }^{\circledR}$, Fresenius Kabi, Deutchland GmbH, Friedberg, Germany) for 30 minutes. During the procedure, his hemodynamic condition was stable, and following the procedure, the hematocrit level was 50\%. We also performed rotational thromboelastometry $\left(\right.$ ROTEM $^{\circledR}$, Pentapharm GmbH, Munich, Germany) analysis, and the results were within the near-normal ranges with the exception of a hypercoagulable state in some results (Table 1).

Table 1. Hematological Labarotory Change in Perioperative State

\begin{tabular}{|c|c|c|c|c|}
\hline & Reference value & $\begin{array}{c}\text { After Acute Normovolemic } \\
\text { Hemodilution }\end{array}$ & After weaning & At end of surgery \\
\hline \multicolumn{5}{|l|}{ EXTEM $^{\circledR}$} \\
\hline $\mathrm{CT}(\mathrm{sec})$ & $38-79$ & 111 & 75 & 80 \\
\hline $\mathrm{CFT}(\mathrm{sec})$ & $34-159$ & 181 & 109 & 72 \\
\hline$A\left({ }^{\prime}\right)$ & $63-83$ & 62 & 69 & 76 \\
\hline $\mathrm{A} 10(\mathrm{~mm})$ & $43-65$ & 40 & 52 & 62 \\
\hline $\mathrm{A} 20(\mathrm{~mm})$ & $50-71$ & 50 & 57 & 66 \\
\hline $\mathrm{MCF}(\mathrm{mm})$ & $50-72$ & 56 & 59 & 67 \\
\hline \multicolumn{5}{|l|}{ FIBTEM $^{\circledR}$} \\
\hline $\mathrm{A} 10(\mathrm{~mm})$ & $7-23$ & 13 & 20 & 13 \\
\hline $\mathrm{A} 20(\mathrm{~mm})$ & $8-24$ & 15 & 26 & 13 \\
\hline $\mathrm{MCF}(\mathrm{mm})$ & $9-25$ & 18 & 28 & 28 \\
\hline Hb, blood (g/dl) & & 17.4 & 14.5 & 11.1 \\
\hline Hematocrit, blood (\%) & & 51 & 43 & 33 \\
\hline
\end{tabular}

a: alpha angle, CT: clotting time, CFT: clot formation time, MCF: maximum clot firmness. A10: amplitude 10 minutes after start of assay, A20: amplitude 20 minutes after start of assay. 


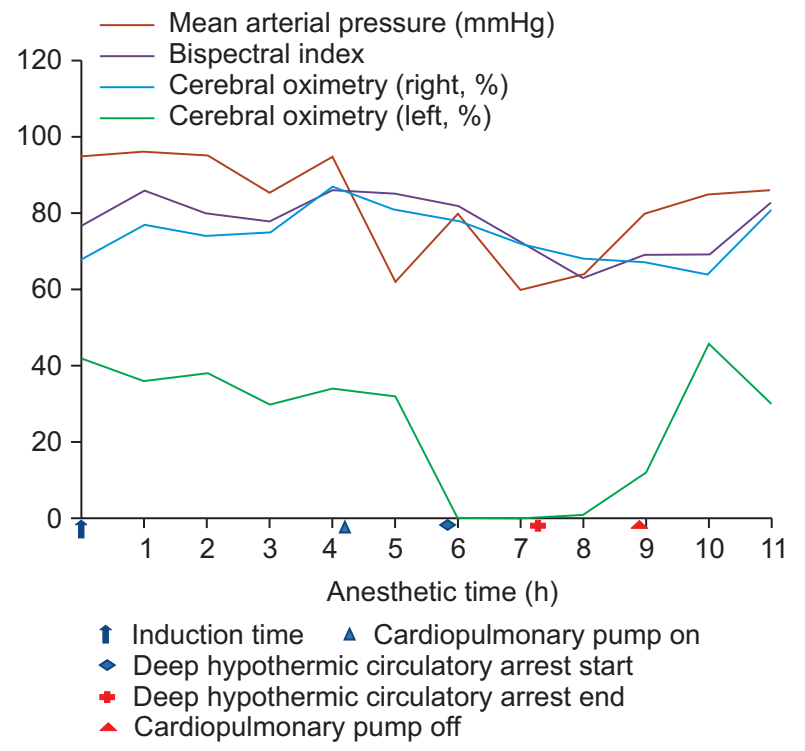

Fig. 1. Mean arterial pressure, bispectral index, cerebral oximeter value change during the operation.

The patient underwent a Bentall operation, hemi-arch replacement, and coronary artery bypass grafting under cardiopulmonary bypass. During the hemi-arch replacement, there was deep hypothermic circulatory arrest for 41 minutes and during that period, icepacks were applied around the patient's head, $500 \mathrm{mg}$ of intravenous pentothal sodium was injected, and cerebral oximetry values were monitored continuously (Fig. 1). While attempting to wean from the cardiopulmonary bypass, his hematocrit level was $43 \%$ (hemoglobin $14.5 \mathrm{~g} / \mathrm{dl}$ ) and in the ROTEM ${ }^{\circledR}$ analysis, the results of EXTEM $^{\circledR}$ showed normal values. The results of FIBTEM ${ }^{\circledR}$ showed a slightly higher amplitude 20 minutes after the start of assay (A20), and maximal clot formation (MCF) in the upper normal range indicating a hypercoagulable state. At the end of surgical wound closure following protamine reversal, surgeons complained that there was a lot of microvascular bleeding, inconsistent with our ROTEM ${ }^{\circledR}$ analysis. Even though the hematocrit was $29 \%$ and our transfusion guideline was not satisfied, two units of packed RBCs, 10 units of cryoprecipitate, 10 units of platelets, and two units of fresh frozen plasma were transfused. The ROTEM ${ }^{\circledR}$ analysis at the end of the surgery were within normal ranges. During the whole operation period, the values of cerebral oximetry on both hemispheres were shown to be above $60 \%$, and for fluid management during the operation, we used crystalloid, with the exception of $650 \mathrm{ml}$ colloid for ANH.

Following transfer to the intensive care unit, his mental recovery was delayed until postoperative day 1 , and the postoperative brain MRI showed an acute ischemic embolic infarct in the right basal ganglia. After starting heparinization, his neurologi- cal problems resolved fully, he was discharged from the hospital on postoperative day 13 with no neurological sequelae and without any postoperative bleeding problems.

\section{Discussion}

Polycythemia vera is a chronic myeloproliferative disorder characterized by excessive red blood cell production [1], and is more common in men, with a prevalence of $4-16 /$ million. In patients with polycythemia vera, increased circulating red blood cells are associated with hyperviscosity of the blood, which can lead to an increased risk of thrombotic complications such as cerebrovascular accidents, myocardial infarction, or peripheral vascular events. Moreover, approximately half of the patients with polycythemia vera also have proliferation of all blood cell lines, causing thrombocytosis and leukocytosis [2,3]. In a previous survey relating to postoperative outcomes in patients with polycythemia vera, an increased risk of both vascular occlusive (7.7\%) and hemorrhagic (7.3\%) complications have been reported [3]. Despite the increased platelet level, abnormal platelet function such as decreased platelet factor 3, reduced platelet adhesiveness, and abnormal platelet aggregation, may in fact be associated with a paradoxical bleeding risk [4].

In order to be positively diagnosed with polycythemia vera, two major criteria and one minor criterion or the first major criterion together with two minor criteria are required. Major criteria include 1) hemoglobin > $18.5 \mathrm{~g} / \mathrm{dl}$ in men, > $16.5 \mathrm{~g} / \mathrm{dl}$ in women, 2) presence of the JAK2 V617F or similar mutation. Minor criteria include 1) bone marrow biopsy showing myeloproliferation, 2) serum erythropoietin level below the normal range, and 3) endogenous erythroid colony formation in vitro [5]. With polycythemia vera having bleeding tendency, it is necessary to distinguish this condition from secondary polycythemia [2]. It seems likely that this patient suffered from secondary polycythemia, because he had chronic hypoxia. In our case, primary polycythemia vera was suggested from the patient's preoperative hemoglobin and hematocrit levels of $20.4 \mathrm{~g} / \mathrm{dl}$ and $61.8 \%$, respectively, and from the results of his blood tests such as thrombocytosis (> 400,000 platelets $/ \mathrm{mm}^{3}$ ), leukocytosis $\left(>120,000 / \mathrm{mm}^{3}\right)$, positive JAK gene mutation, and a low level of serum erythropoietin.

Several perioperative pretreatments can be considered to prevent perioperative thromboembolic complications in patients with polycythemia vera, such as the use of low-dose heparin, a course of weekly phlebotomy to reduce hematocrit to below $45 \%$, or intraoperative acute normovolemic hemodilution, extracting blood that is simultaneously replaced by colloids until the $\mathrm{Hb}$ is reduced to $14.5 \mathrm{~g} / \mathrm{dl}$ with a hematocrit level of $45 \%$ [6]. In this case, as the patient had an emergency operation, ANH was the only available technique. Our target hematocrit level 
after ANH (50\%) was slightly higher than recommended [6], due to the patient having concomitant ischemic heart disease and several risk factors for post-procedural bleeding, such as the use of a large dose of heparin for the cardiopulmonary bypass, re-sternotomy, and deep hypothermic circulatory arrest that is usually associated with decreased coagulation factor activation, platelet dysfunction, and excessive fibrinolysis resulting in a bleeding diathesis $[7,8]$. ANH extracted volume $(650 \mathrm{ml})$ was calculated as followed $\mathrm{V}=\mathrm{EBV} \times(\mathrm{Ho}-\mathrm{Hf}) / \mathrm{Hav}$, initial hematocrit (Ho, this patient; 60\%), minimum allowable hematocrit (Hf, this patient; 50\%), average hematocrit (Hav, this patient; $55 \%$ ), estimated blood volume (EBV, this patient; $50 \mathrm{~kg} \times 70 \mathrm{ml} /$ $\mathrm{kg}$ ), volume (V) $[9,10]$.

There have been a few reports of intraoperative $\mathrm{ANH}$ in polycythemic patients undergoing cardiovascular surgery with or without cardiopulmonary bypass. Arora et al. [11] reported a case of off-pump coronary artery bypass grafting in a polycythemic patient having preoperative hemoglobin of $20.1 \mathrm{~g} / \mathrm{dl}$ and hematocrit of $60.3 \%$. They performed ANH through the venous sheath $(650 \mathrm{ml}$ of $6 \%$ HES colloid was used as replacement fluid after 2 units of blood) and hemoglobin was reduced to $16 \mathrm{~g} / \mathrm{dl}$. Alfirevic et al. [7] reported a polycythemic patient with preoperative hematocrit of $51 \%$ undergoing aortic dissection repair, and intraoperative $\mathrm{ANH}$ was performed to reduce the hematocrit level to $44 \%$. In these two patient cases, no perioperative complications were reported.

Although ANH should be applied with caution in patients with ischemic heart disease, some previous studies reported its protective effects in patients undergoing coronary arterial bypass grafting. Licker et al. $[12,13]$ demonstrated that $\mathrm{ANH}$ has cardio-protective effects by lowering blood viscosity in patients undergoing coronary artery bypass surgery with aortic cross clamping. Lowered blood viscosity can improve coronary arterial perfusion, cardiac output, higher oxygen extraction ratios and oxygen delivery to the underperfused myocardial area.
We used $650 \mathrm{ml}$ HES colloid only during the ANH procedure. Recently, we have been reluctant to use HES colloid in $\mathrm{CPB}$, depending on the operation, due to raised concerns about the increasing bleeding risk [14]. However, HES colloid was used at a relatively low risk in hypercoagulable status of PV.

The thromboelastographic pattern in polycythemia vera shows minute changes in reaction time and maximal amplitude and a significant increase in the alpha angle, indicating a hypercoagulable state [15]. In our case, we performed ROTEM ${ }^{\circledR}$ analysis three times during the operation, and the majority of the results were near-normal and close to baseline (after ANH) showing a hypercoagulable state (prolongated clotting time, clot formation time) consistent with previous reports. However, the patient suffered from microvascular bleeding of the surgical field after weaning from cardiopulmonary bypass, which is inconsistent with our ROTEM ${ }^{\circledR}$ analysis. This may suggest that although the amounts of fibrinogen and platelets are increased in a polycythemia vera patient, platelet function may have been deficient, and thus associated with paradoxical bleeding [4]. Our limitation was the platelet function test, as the platelet count was not evaluated during the operation or postoperatively.

The patient had a transient ischemic infarction postoperatively. The actual cause of the event could not be determined, however there were several related risk factors for postoperative cerebral accidents, such as the use of cardiopulmonary bypass, deep hypothermic circulatory arrest, and the presence of polycythemia. Fortunately, the patient was discharged from the hospital with no apparent neurological sequelae, and there has been no further event during the postoperative follow-up period.

In conclusion, optimizing the hemostatic balance is important but challenging in a patient with polycythemia vera. Thus, the results of conventional coagulation tests or ROTEM ${ }^{\circledR}$ analysis could be used carefully with consideration of the actual clinical situation in a patient with polycythemia vera.

\section{References}

1. Al-Fadhli J, Al-Shammari F, Al-Duaij A, Al-Sarraf N. Coronary artery bypass grafting in a patient with polycythaemia rubra vera - a rare indication with a spectrum of complication: a case report. Cases J 2009; 2: 8126.

2. Berk PD, Goldberg JD, Donovan PB, Fruchtman SM, Berlin NI, Wasserman LR. Therapeutic recommendations in polycythemia vera based on Polycythemia Vera Study Group protocols. Semin Hematol 1986; 23: 132-43.

3. Ruggeri M, Rodeghiero F, Tosetto A, Castaman G, Scognamiglio F, Finazzi G, et al. Postsurgery outcomes in patients with polycythemia vera and essential thrombocythemia: a retrospective survey. Blood 2008; 111: 666-71.

4. Berger S, Aledort LM, Gilbert HS, Hanson JP, Wasserman LR. Abnormalities of platelet function in patients with polycythemia vera. Cancer Res 1973; 33: 2683-7.

5. Wadleigh M, Tefferi A. Classification and diagnosis of myeloproliferative neoplasms according to the 2008 World Health Organization criteria. Int J Hematol 2010; 91: 174-9.

6. Cundy J. The perioperative management of patients with polycythaemia. Ann R Coll Surg Engl 1980; 62: 470-5.

7. Alfirevic A, Duncan AI, Starr N. Isovolemic hemodilution in a patient with polycythemia vera undergoing deep hypothermic circulatory 
arrest. Can J Anaesth 2007; 54: 402-3.

8. Wilde JT. Hematological consequences of profound hypothermic circulatory arrest and aortic dissection. J Card Surg 1997; 12(2 Suppl): 201-6.

9. Meier J, Kleen M, Habler O, Kemming G, Messmer K. New mathematical model for the correct prediction of the exchangeable blood volume during acute normovolemic hemodilution. Acta Anaesthesiol Scand 2003; 47: 37-45.

10. Shander A, Rijhwani TS. Acute normovolemic hemodilution. Transfusion 2004; 44(12 Suppl): 26S-34S.

11. Arora D, Juneja R, Pendarkar D, Mehta Y, Trehan N. Off-pump coronary artery bypass grafting in a polycythaemic patient--case report and review of literature. Ann Card Anaesth 2007; 10: 54-7.

12. Licker M, Ellenberger C, Sierra J, Kalangos A, Diaper J, Morel D. Cardioprotective effects of acute normovolemic hemodilution in patients undergoing coronary artery bypass surgery. Chest 2005; 128: 838-47.

13. Licker M, Sierra J, Tassaux D, Diaper J. Continuous haemodynamic monitoring using transoesophageal Doppler during acute normovolaemic haemodilution in patients with coronary artery disease. Anaesthesia 2004; 59: 108-15.

14. Schramko A, Suojaranta-Ylinen R, Niemi T, Pesonen E, Kuitunen A, Raivio P, et al. The use of balanced HES 130/0.42 during complex cardiac surgery; effect on blood coagulation and fluid balance: a randomized controlled trial. Perfusion 2015; 30: 224-32.

15. Reikvam H, Steien E, Hauge B, Liseth K, Hagen KG, Storkson R, et al. Thrombelastography. Transfus Apher Sci 2009; 40: 119-23. 